\title{
Model Molecules for Evaluating Asphaltene Precipitation Onset of Crude Oils
}

\author{
Rita C. P. Nunes, ${ }^{a}$ Michel R. T. Valle, ${ }^{b}$ William R. D. Reis, ${ }^{b}$ Thiago M. Aversa, ${ }^{b, c}$ \\ Sofia D. Filipakis ${ }^{a}$ and Elizabete F. Lucas ${ }^{\oplus *, a, b}$
}

\author{
${ }^{a}$ COPPE/PEMM/LADPOL, Universidade Federal do Rio de Janeiro, \\ Av. Horácio Macedo, 2030, Bloco F, 21941-598 Rio de Janeiro-RJ, Brazil
}

${ }^{b} I M A / L M C P$, Universidade Federal do Rio de Janeiro, Av. Horácio Macedo, 2030, Bloco J, 21941-598 Rio de Janeiro-RJ, Brazil

'Instituto Federal de Educação, Ciência e Tecnologia do Rio de Janeiro (IFRJ), Av. República do Paraguai, 120, 25050-100 Duque de Caxias-RJ, Brazil

\begin{abstract}
Predicting the compatibility of crude oils from different streams can be done by applying models that use the solubility parameter of the oils. The approximate solubility parameter value of a given crude oil can be calculated by observing the asphaltene precipitation onset caused by titration with $n$-heptane. For oils whose precipitation onset is not well defined, a small quantity of another petroleum with easily detected onset can be added. It would be ideal to always use the same petroleum for this addition, but this is obviously not possible. The purpose of this study was to replace this petroleum by a synthetic molecule. Therefore, molecules were selected and synthesized to obtain structures containing aromatic ring, aliphatic chain and heteroatom. The molecules were characterized by infrared spectrometry, gas chromatography-mass spectrometry, elemental analysis and gel permeation chromatography. Nitrated cardanol, polycardanol obtained by addition polymerization (PCA) and nitrated PCA presented the desired behavior. However, the concentration of the molecule in toluene needs to be adjusted in function of the characteristics of the petroleum. For a particular crude oil, when model molecule present solubility in a wider solubility parameter range, lower concentration will require to identify the precipitation onset of that oil.
\end{abstract}

Keywords: asphaltenes, precipitation onset, near infrared, model molecules

\section{Introduction}

Crude oils from different streams are typically mixed before primary processing at refineries. However, incompatibility between these oils can lead to precipitation of asphaltenes, which is undesirable. ${ }^{1-7}$ Asphaltenes can be defined, based on their structure, as molecules with relatively high molar mass composed of condensed aromatic rings, cyclic structures, and a small number of aliphatic hydrocarbon chains, as well as functional groups (such as carbonyl, amine and hydroxyl) and elements (such as sulfur, nickel and vanadium). Since asphaltenes are a class of molecules that can be separated from crude oil or distillation residue by the difference of solubility parameters in distinct solvents, it is common for asphaltenes to be defined as the fraction of crude oil that is insoluble in short-chain $n$-alkanes and soluble in monoaromatic solvents

*e-mail: elucas@metalmat.ufrj.br like benzene and toluene. The stability of the asphaltene fractions in petroleum has been widely studied, ${ }^{8-12}$ and one of the main factors that acts to destabilize asphaltenes in oil mixtures is the variation of composition. ${ }^{13-16}$

To predict the compatibility of crude oils and, consequently, the stability of the asphaltenes in their mixture, models have been proposed, some based on values of the Hildebrand solubility parameter $(\delta)$ of the oils. ${ }^{717-20}$ However, the experimental determination of $\delta$ is not trivial, so the approximation denoted by equation 1 has been used, assuming the solubility parameter of the mixture $\left(\delta_{\mathrm{M}}\right)$ equal to $16.35 \mathrm{MPa}^{1 / 2}{ }^{17}$ This approximation assumes that the asphaltene precipitation occurs at a fixed point (flocculation point) of $16.35 \mathrm{MPa}^{1 / 2}$. The solubility parameter of a particular petroleum $\left(\delta_{p}\right)$ can then be calculated by precipitation onset testing involving titration of the crude oil sample with $n$-heptane, to obtain the parameters of equation 1: $\varphi_{\mathrm{h}}$, which is the fraction by volume of $n$-heptane at the precipitation onset; and $\varphi_{\mathrm{p}}$, 
which is the fraction by volume of oil in relation to the volume of $n$-heptane added. The solubility parameter of $n$-heptane, $\delta_{\mathrm{h}}$, is available in the literature. ${ }^{21}$

$\delta_{\mathrm{M}}=\delta_{\mathrm{h}} \varphi_{\mathrm{h}}+\delta_{\mathrm{p}} \varphi_{\mathrm{p}}$

The asphaltene precipitation onset by titration with $n$-heptane can be monitored by techniques such as optical microscopy (magnification of 200x) ) $^{4,22,23}$ and near-infrared spectroscopy (NIR). ${ }^{24-30}$ For optical microscopy, aliquots of oil after addition of determined volumes of $n$-heptane are observed under the microscope until detecting the appearance of asphaltene particles. ${ }^{4,22,23}$ In turn, NIR is used to monitor the absorption intensity of the sample during titration with $n$-heptane: the dilution of the sample leads to a reduction of the absorption intensity, while the appearance of particles causes this intensity to increase. Therefore, the precipitation onset is based on the volume of $n$-heptane necessary to reach the minimum absorption intensity. The precipitation onset is thus expressed in terms of the volume of $n$-heptane $(\mathrm{mL})$ necessary to induce the start of asphaltene precipitation from $1 \mathrm{~g}$ of petroleum. The oil is considered more stable the greater the volume of $n$-heptane necessary to cause the asphaltenes to precipitate. ${ }^{24-30}$

Ascertaining the solubility parameter of a crude oil sample by experimental determination of the asphaltene precipitation onset is unreliable when this onset point is hard to detect. This occurs when visualization of the particles by optical microscopy is difficult and the absorption intensity curve in function of $n$-heptane volume is poorly defined. This limitation can be overcome by estimating the precipitation onset by mixing the target petroleum with another crude oil that has well-defined precipitation onset, called the standard petroleum. ${ }^{30,31}$ Based on this experimental procedure, the solubility parameter of the target oil $\left(\delta_{\mathrm{p}}\right)$ can be calculated by using equation $2 .{ }^{17}$

$\delta_{\mathrm{M}}=\delta_{\mathrm{h}} \varphi_{\mathrm{h}}+\delta_{\mathrm{p}} \varphi_{\mathrm{p}}+\delta_{\mathrm{sp}} \varphi_{\mathrm{sp}}$

where $\delta_{\mathrm{h}}, \delta_{\mathrm{p}}, \delta_{\mathrm{sp}}$ are the respective solubility parameters of $n$-heptane, the target petroleum and the standard petroleum, and $\varphi_{\mathrm{h}}, \varphi_{\mathrm{p}}, \varphi_{\mathrm{sp}}$ are the fractions by volume of $n$-heptane, target petroleum and standard petroleum in the final mixture at the flocculation point.

In a previous study, ${ }^{30}$ a Brazilian crude oil, called APS, was used as the standard to determine the precipitation onset and hence the solubility parameter of two other oils. Since the solubility parameter values obtained are not exactly equal to those determined directly by using the precipitation onset of the target oil sample itself, it is necessary that the standard petroleum always to be the same. This is only possible when the same type of petroleum is produced. An alternative to this method can be implemented by using synthetic molecules instead of the standard petroleum, tailored to have similar behavior when added to oil samples for which it is hard to detect the precipitation onset.

Some studies have been carried out to investigate model asphaltene molecules. The modeling of the chemical structure and reactivity of the asphaltenes enables, for instance, predicting the formation of coke and the properties of various refinery processes, allowing reduction of costs. ${ }^{32}$ The chemical characterization of asphaltenes has been widely investigated. Based on characterization results obtained, for example, from nuclear magnetic resonance (NMR), Fourier-transform ion cyclotron resonancemass spectrometry (FTICR-MS) and collision-induced dissociation (CID) mass spectrometry, researchers have suggested that asphaltene molecules contain a large polynuclear aromatic (PNA) nucleus with smaller aromatic rings linked to it. The nucleus is basically composed of aromatics, but also contains naphthenic compounds. Several structures have been proposed to model asphaltene molecules, the main ones being the continental and archipelago models. ${ }^{33-38}$

Based on characterization results of asphaltene fractions obtained by solid-state NMR, X-ray photoelectron spectroscopy (XPS) and elemental analysis, molecular structures have been proposed for different types of crude oil, with the objective of simulating the cracking behavior of vacuum distillation residues. ${ }^{39}$ Some model molecules have been used to reproduce the breakdown behavior of the molecular structures of vacuum residues during thermolysis for condensation and cracking reactions. ${ }^{40}$ Among these are model molecules based on octaethylporphyrin, $N, N^{\prime}$-ditridecyl-3,4,9,10-perylenetetracarboximide, aromatic and aliphatic blocks with molar mass of $750 \mathrm{~g} \mathrm{~mol}^{-1}$ and quinoline- $65 .{ }^{32,41-45}$ For the purpose of assessing the properties of the asphaltenes and the underlying mechanisms involved in these properties, various researchers have studied different model molecules, such as those based on pyrene, coronene, pyridine, and quinoline, always containing an aromatic core and hydrophobic alkyl chains. . $^{34,36-38,46-50}$

Molecular simulation has also been employed to improve the relation between the physico-mechanical properties of model molecules and those of real asphaltenes, ${ }^{34,37,50-52}$ as well as to shed light on the aggregation and separation of asphaltenes in binary solvent systems..$^{34,36-38}$

As already mentioned, in a previous work, ${ }^{30}$ we used a petroleum defined as standard (APS) to improve the profile of absorption curve (by NIR) of crude oils called APA and $\mathrm{APB}$ in function of the volume of $n$-heptane titrated. In this 


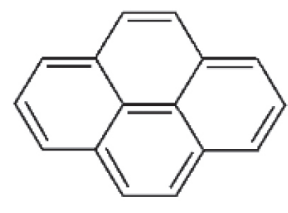

(a)<smiles>c1ccc2ncccc2c1</smiles>

(b)

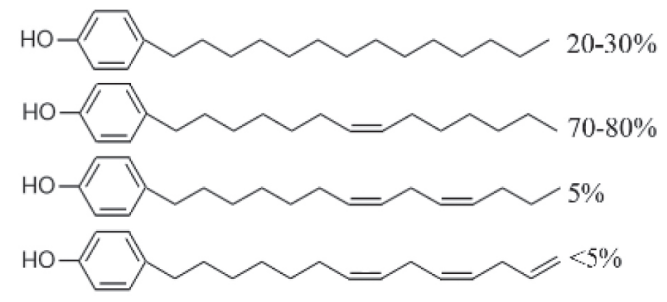

(c)

Figure 1. Chemical structure of (a) pyrene; (b) quinoline and (c) cardanol (adapted from reference 53).

study, we synthesized and characterized model molecules to be added to these two crude oils, seeking to find systems whose asphaltenes precipitation onset values are close to those obtained by the addition of APS.

\section{Experimental}

Materials

$n$-Heptane $99.5 \%$, pyrene practical grade (P.A.) (Figure 1a), formaldehyde P.A., boron trifluoride-diethyl etherate $\left(\mathrm{BF}_{3} \cdot \mathrm{O}\left(\mathrm{C}_{2} \mathrm{H}_{5}\right)_{2}\right) 99.9 \%$, oxalic acid $99.5 \%$, sulfuric acid P.A., methanol P.A., dichloromethane P.A., nitric acid $65 \%$ P.A., hydrochloric acid P.A., anhydrous sodium sulfate P.A., 95\% ethyl alcohol (ethanol) ACS P.A. and commercial toluene (further distilled and dried on alumina) were supplied by Vetec Quimica Fina Ltda. (Duque de Caxias, Brazil). Quinoline 97\% (Figure 1b), epichlorohydrin 99.9\%, hexanoyl chloride 98\%, nonylphenol and anhydrous aluminum chloride $\leq 99 \%$ were supplied by SigmaAldrich (São Paulo, Brazil). Tetrahydrofuran (THF) P.A. was supplied by Tedia, (Rio de Janeiro, Brazil). Cardanol (Figure 1c, presenting the approximate concentrations of the components of the mixture $)^{41}$ was supplied by Satya Cashew Chemicals (Tamil Nadu, India). Water was distilled and deionized by a Quimis system (São Paulo, Brazil).

Four crude oils samples, extracted from Brazilian fields (called APS, APA, APB and APX) and asphaltenes C3I extracted ${ }^{54}$ from APS were donated by Petrobras. The relevant characteristics of these samples (Table 1) were published previously. ${ }^{30}$

Table 1. Some characteristics of crude oils named APS, APA and APB CENPES/Petrobras ${ }^{33}$

\begin{tabular}{lccc}
\hline Crude oil sample & APS & APA & APB \\
\hline Density / $\left(\mathrm{g} \mathrm{cm}^{-3}\right)$ & 0.976 & 0.935 & 0.880 \\
API gravity / degree & 13.0 & 14.8 & 31.0 \\
Asphaltenes / m/m\% & 6.20 & 3.6 & $<0.5$ \\
Water content (Karl Fisher) / m/m\% & 0.05 & 0.09 & 0.03 \\
\hline
\end{tabular}

API: American Petroleum Institute.

\section{Synthesis of molecules}

Pyrene was chemically modified (acylated) utilizing $2.97 \mathrm{~mol}$ of pyrene, $2.47 \mathrm{~mol}$ of hexanoyl chloride and $0.99 \mathrm{~mol}$ of $\mathrm{AlCl}_{3}$. Dichloromethane was used as solvent. The mixing was carried out in an ice bath with magnetic stirring, which was kept for $5 \mathrm{~h}$ at $70{ }^{\circ} \mathrm{C}$. The reaction was stopped with ice and addition of $1 \mathrm{~mL}$ of hydrochloric acid $(\mathrm{HCl})$. The final product was removed from the aqueous phase by decantation.

Cardanol was nitrated utilizing $1 \mathrm{~mol}$ of cardanol, $1 \mathrm{~mol}$ of nitric acid and methanol as solvent, at room temperature for 30 min under magnetic stirring. At the end of the reaction, $10 \mathrm{~mL}$ of ethyl acetate was added and the solvent was evaporated at room temperature.

The cardanol epoxidation reaction was performed using $0.01 \mathrm{~mol}$ of cardanol in a $\mathrm{NaOH}$ solution and $0.04 \mathrm{~mol}$ of epichlorohydrin (added dropwise). The reaction was kept under magnetic stirring for $18 \mathrm{~h}$ at room temperature. Then $50 \mathrm{~mL}$ of dichloromethane and ethanol mixture was added under magnetic stirring to form two phases. The final product was separated in a separation funnel, washed with distilled water and dried with anhydrous sodium sulfate.

Nonylphenol was nitrated using $1 \mathrm{~mol}$ of nonylphenol, $1 \mathrm{~mol}$ of nitric acid and methanol as solvent, for $30 \mathrm{~min}$ at room temperature. Then $10 \mathrm{~mL}$ of ethyl acetate was added and the solvent was evaporated at room temperature.

Polycardanol, called PCC0, was synthesized by polycondensation employing a molar ratio of 1:0.8 (cardanol:formaldehyde) with addition of sulfuric acid. The reaction time was $2 \mathrm{~h}$ at temperature of $140^{\circ} \mathrm{C}$, after which $75 \mathrm{~mL}$ of distilled water was added to the reaction mass followed by filtration through a separation funnel to remove the aqueous phase. Polycardanol samples, named PCC1, PCC2 and PCC3, were synthesized by polycondensation. To obtain PCC1, $40 \mathrm{~mL}$ of cardanol, $13.8 \mathrm{~mL}$ of formaldehyde and $0.42 \mathrm{~g}$ of dihydrated oxalic acid were used, dissolved in $2.5 \mathrm{~mL}$ of methanol. The same reaction conditions were employed to obtain PCC2 except that the oxalic acid was added directly in the reaction solution, while to synthesize PCC3, oxalic acid was added in two steps: at the start of 
the reaction and after $1 \mathrm{~h}$. The general structure of the PCC molecule is represented by Figure $2 \mathrm{a}$.

Polycardanol, called PCA, was synthesized by polyaddition via cationic initiation. For this purpose, $30 \mathrm{~mL}$ of cardanol in $0.3 \mathrm{~mL}$ of boron trifluoride-diethyl etherate $\left(\mathrm{BF}_{3} . \mathrm{O}\left(\mathrm{C}_{2} \mathrm{H}_{5}\right)_{2}\right)$ reacted under an inert atmosphere in a glove bag. The reaction time was $2 \mathrm{~h}$ and the temperature was $140^{\circ} \mathrm{C}$. After this, the reaction was stopped by placing the system in an ice bath. The general structure of PCA molecule is represented by Figure $2 b$.

PCA was nitrated utilizing $0.002 \mathrm{~mol}$ of cardanol, $0.02 \mathrm{~mol}$ of nitric acid and dichloromethane as solvent, at room temperature for $30 \mathrm{~min}$ under magnetic stirring. At the end of the reaction, $10 \mathrm{~mL}$ of ethyl acetate was added and the solvent was evaporated at room temperature.

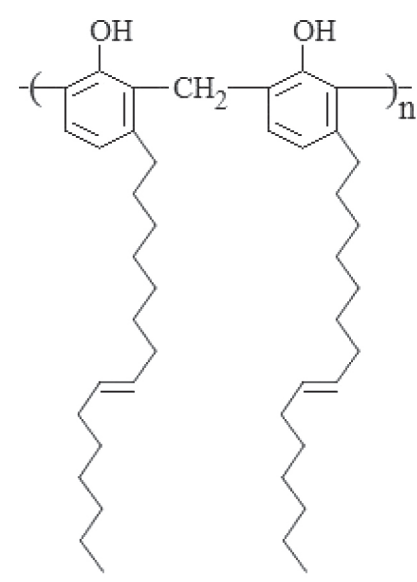

(a)

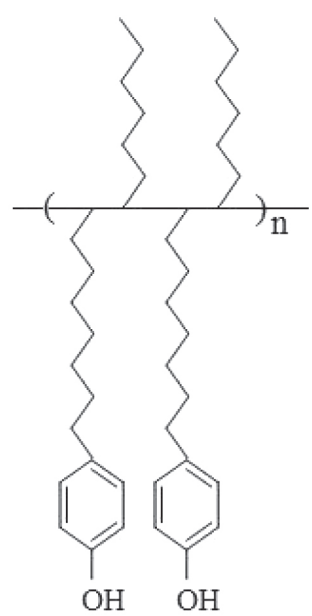

(b)
Figure 2. Molecular structures of polycardanol obtained by (a) polycondensation (PCC) and (b) polyaddition (PCA).

\section{Characterization of the molecules}

All synthesized molecules were characterized by Fourier-transform infrared spectrometry (FTIR) using a PerkinElmer Frontier spectrometer (Waltham, USA), except for the acyl pyrene and nitrated nonylphenol molecules. The samples were analyzed in $\mathrm{KBr}$ pellets and the spectra were obtained with a scan from 4000 to $400 \mathrm{~cm}^{-1}$ with resolution of $4 \mathrm{~cm}^{-1}$ at room temperature.

Polycardanol samples were also characterized by gel permeation chromatography (GPC) using a Viscotek Max GPC system (São Paulo, Brazil) and a VE 2001 GPC solvent/sample module. The sample was prepared at a concentration of $10 \mathrm{mg} \mathrm{mL}^{-1}$ in tetrahydrofuran (THF). A Shodex KF-806M column (exclusion limit of $2 \times 10^{7}$ ) was used at a flow of $1 \mathrm{~mL} \mathrm{~min}{ }^{-1}$ and temperature of $25^{\circ} \mathrm{C}$.
Pyrene and acyl pyrene were characterized with a Shimadzu GCMS-QP2010 Ultra gas chromatograph mass spectrometer (São Paulo, Brazil) with an RTX-DB5 column at a flow of $1 \mathrm{~mL} \mathrm{~min}^{-1}$, initial temperature of $150^{\circ} \mathrm{C}$, final temperature of $280^{\circ} \mathrm{C}$ and heating rate of $30^{\circ} \mathrm{C} \mathrm{min}^{-1}$. The injector and detector temperatures were 250 and $280^{\circ} \mathrm{C}$, respectively.

The samples containing a nitro group $\left(\mathrm{NO}_{2}\right)$ in their structure (nitrated cardanol, nitrated PCA and nitrated nonylphenol) were quantified using elemental analysis (CHN/O), with a PerkinElmer 2400 CHNS/O Series II system (Waltham, USA). Between 2.0 and $2.5 \mathrm{mg}$ of sample was weighed on a precision scale and placed in a tin capsule. The material was then burned in a combustion chamber at a combustion temperature of $975{ }^{\circ} \mathrm{C}$ and reduction temperature of $500{ }^{\circ} \mathrm{C}$. The analyses were performed in duplicate and the oxygen percentage was determined by mass difference.

Preparation of the model systems

The model systems were prepared with 15 and $30 \mathrm{wt} . \%$ of asphaltenes C3I in toluene, utilizing 1.05 and $2.10 \mathrm{~g}$ of asphaltenes $\mathrm{C} 3 \mathrm{I}$ in toluene, respectively.

Determination of asphaltene precipitation onset using NIR

The precipitation onset was determined at $1600 \mathrm{~nm}$, using Bruker MATRIX-F near-infrared (NIR) spectrophotometer system (Billerica, USA), ${ }^{23,25,55}$ operating with the Opus 6.5 software, connected to a Jasco PU 2087 Plus displacement pump. $7 \mathrm{~g}$ of the previously prepared asphaltene solution was poured into the device's cup while kept under constant magnetic stirring. Then a probe with $5 \mathrm{~mm}$ optical path was introduced in the cup and the system was turned on simultaneously with the start of titration of the flocculant, at a flow of $0.1 \mathrm{~mL} \mathrm{~min}{ }^{-1}$. After $8 \mathrm{~h}$ and use of all $48 \mathrm{~mL}$ of flocculant, the analysis was finalized and a graph of absorbance versus volume of $n$-heptane was plotted, revealing the volume of $n$-heptane corresponding to the minimum absorbance point, indicating onset of asphaltenes precipitation. The asphaltenes precipitation onset was obtained by dividing the $n$-heptane volume by 7 , since the onset is expressed in terms of $\mathrm{mL}$ of $n$-heptane per $\mathrm{g}$ of oil phase. The assays were conducted in duplicate and for almost all samples the values were calculated from the mean of the two measures. The maximum error found was $<3 \% .{ }^{30}$

\section{Results and Discussion}

The molecules and their chemical modification 
reactions were selected based on the literature regarding the molecular structure of asphaltenes, as described in the Introduction section. Therefore, molecules containing aromatic rings, condensed aromatic rings, aromatic ring containing a heteroatom, and aromatic ring containing an aliphatic hydrocarbon chain and heteroatom were utilized to determine the asphaltene precipitation onset of the crude oil samples.

\section{Characterization of the synthesized molecules}

To obtain molecules that could be added to a crude oil sample to improve the identification of the asphaltenes precipitation onset by the procedure of titration with $n$-heptane and detection by NIR, as can be obtained by adding an oil sample defined as a standard (APS), we synthesized structures containing aromatic rings and hydrocarbon chains and/or hydrophilic groups. Specifically, we synthesized acyl pyrene, nitrated cardanol, epoxylated cardanol and nitrated nonylphenol, along with polycardanol by polyaddition (PCA) and polycardanol by polycondensation (PCC), in which the aromatic rings are, respectively, farther and nearer each other in the polymer structure (Figure 2). Finally, the addition polycardanol (PCA) sample was nitrated to produce PCAN.

The FTIR spectra confirmed that molecules of polycardanol were obtained by PCA and PCC, as well as that structural modifications of the cardanol (nitration and epoxidation) and polycardanol (nitration) were achieved. The unreacted cardanol (C) and the synthesized samples of PCC (Figure 3a) and PCA (Figure 3b) had the same absorption bands. For the PCA and PCC, bands were observed at $3350 \mathrm{~cm}^{-1}$, related to the $\mathrm{OH}$ axial deformation,
$2967 \mathrm{~cm}^{-1}$, referring to the $\mathrm{CH}$ axial deformation of olefins, 2926- $2856 \mathrm{~cm}^{-1}$, associated with the $\mathrm{CH}$ axial deformation, $2000-1650 \mathrm{~cm}^{-1}$, referring to the substituted meta aromatic ring, $1590 \mathrm{~cm}^{-1}$, related to the axial deformation of the $\mathrm{C}=\mathrm{C}$ bonds, $1456 \mathrm{~cm}^{-1}$, referring to the axial deformation of the $\mathrm{C}=\mathrm{C}$ bonds of the aromatic ring, and $1267 \mathrm{~cm}^{-1}$, referring to the axial $\mathrm{C}-\mathrm{O}$ deformation. These results are in line with those obtained previously with synthesized samples following the same reaction methods of polyaddition and polycondensation. ${ }^{27,56}$ The polycondensation reaction can be confirmed by the relative increase of intensity of the band associated with deformation of the $\mathrm{C}-\mathrm{H}$ bond due to the insertion of a $\mathrm{CH}_{2}$ group between each aromatic ring (Figure $3 \mathrm{a}$ ). All the products of this type of reaction presented very similar spectra. The polyaddition reaction was confirmed by the relative reduction of the band associated with the $\mathrm{C}=\mathrm{C}$ bond, since this reaction occurs by the opening of the double bond. This band did not totally disappear because cardanol is composed of a mixture of molecules (Figure 1c) and the reaction product is a polymer mixture with unreacted species, containing or not containing double bonds.

The FTIR spectra also confirmed the nitration of cardanol (Figure 3c), nitration of addition polycardanol (Figure 3d) and epoxidation of cardanol (Figure 3e). The nitration of cardanol and polycardanol was confirmed by the presence of asymmetric axial deformation of the nitro group $\left(\mathrm{NO}_{2}\right)$ at $1620 \mathrm{~cm}^{-1}$ and symmetric deformation at $1521-1329 \mathrm{~cm}^{-1}$. The epoxidation of cardanol was confirmed by the presence of asymmetric axial deformation of $\mathrm{C}-\mathrm{O}-\mathrm{C}$ at $1127 \mathrm{~cm}^{-1}$ and symmetric axial deformation at $1035 \mathrm{~cm}^{-1} .{ }^{57}$

The molar mass results of the polycardanol samples, presented in Table 2, show that condensation polycardanol (a)

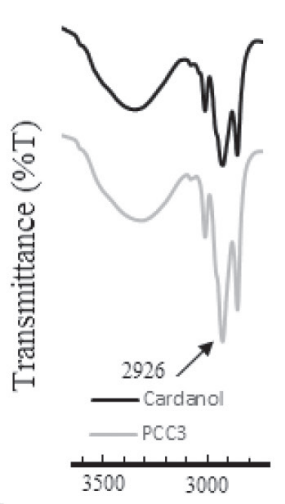

(b)
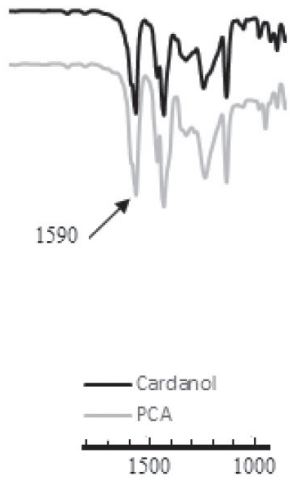

(c)
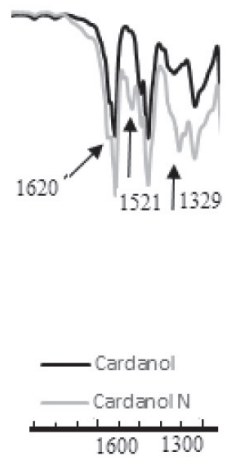

(d)
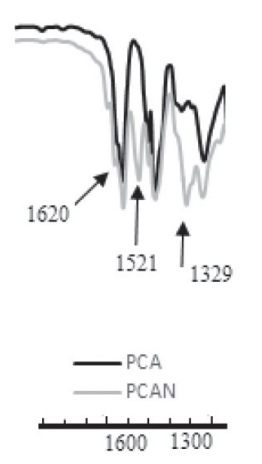

(e)
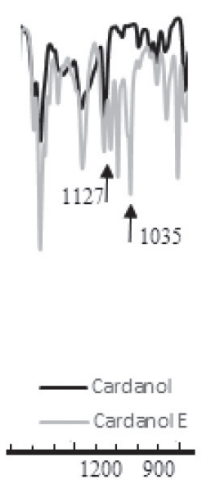

\section{Wavelenght $\left(\mathrm{cm}^{-1}\right)$}

Figure 3. FTIR spectra of cardanol and polycardanol samples: (a) cardanol (black) and polycardanol by condensation (PCC) (grey); (b) cardanol (black) and polycardanol by addition (PCA) (grey); (c) cardanol (black) and cardanol nitrated (grey); (d) polycardanol by addition (PCA) (black) and the same structure after nitration (PCAN) (grey); (e) cardanol (black) and cardanol epoxidized (grey). 
molecules (PCC) were obtained having varied molar masses and polydispersion values.

Table 2. Number average molar mass $\left(\overline{\mathrm{M}}_{\mathrm{n}}\right)$, weight average molar mass $\left(\overline{\mathrm{M}}_{\mathrm{w}}\right)$ and polydispersity $\left(\overline{\mathrm{M}}_{\mathrm{w}} / \overline{\mathrm{M}}_{\mathrm{n}}\right)$ of polycardanol samples, obtained by gel permeation chromatography

\begin{tabular}{lccc}
\hline Sample & $\overline{\mathrm{M}}_{\mathrm{n}} /\left(\mathrm{g} \mathrm{mol}^{-1}\right)$ & $\overline{\mathrm{M}}_{\mathrm{w}} /\left(\mathrm{g} \mathrm{mol}^{-1}\right)$ & $\overline{\mathrm{M}}_{\mathrm{w}} / \overline{\mathrm{M}}_{\mathrm{n}}$ \\
\hline PCC0 & 1,760 & 7,800 & 4.40 \\
PCC1 & 7,700 & 12,470 & 1.62 \\
PCC2 & 5,580 & 11,020 & 1.98 \\
PCC3 & 4,500 & 12,820 & 2.85 \\
PCA & 1,990 & 7,480 & 3.76 \\
\hline
\end{tabular}

PCC: polycardanol obtained by polycondensation; PCA: polycardanol obtained by polyaddition.

The pyrene and acyl pyrene molecules were characterized by gas chromatography together with mass spectrometry (GC-MS). The analysis was first performed for hexanoyl chloride (reagent used to synthesize the acyl pyrene). Hexanoyl chloride presented a retention time of $4.067 \mathrm{~min}$ and $\mathrm{m} / z+99$ (Figure $4 \mathrm{a}$ ). In turn, pyrene presented a retention time of $7.117 \mathrm{~min}$ and $\mathrm{m} / \mathrm{z}+202$ (Figure 4b), while acyl pyrene, as expected, had a longer retention time of $13.675 \mathrm{~min}$ and $\mathrm{m} / \mathrm{z}+300$ (Figure $4 \mathrm{c}$ ), proving that the acylated product was obtained.

The molecules of nitrated cardanol, nitrated polycardanol (PCAN) and nitrated nonylphenol were quantified by elemental analysis (CHN / O) to identify the nitrogen atom in the molecular structure and thus to confirm the nitration reaction. The percentages by mass of nitrogen were $2.075,0.65$ and $2.69 \mathrm{wt} . \%$, respectively, for nitrated cardanol, nitrated polycardanol (PCAN) and nitrated nonylphenol. Table 3 reports the results converted into average percentage of number of atoms in each type of molecule. Comparison of the average composition values calculated for $100 \%$ conversion by the nitration reaction, i.e., with all the aromatic rings containing a $\mathrm{NO}_{2}$ group, with the values determined by elemental analysis shows nitration percentages of approximately 50, 12.5 and 50\% for nitrated cardanol, nitrated polycardanol (PCAN) and nitrated nonylphenol, respectively.

Table 3. Elemental analyses of nitrated cardanol, nitrated polycardanol (PCAN) and nitrated nonylphenol

\begin{tabular}{lccccc}
\hline Sample & $\begin{array}{c}\text { Carbon / } \\
\mathrm{m} / \mathrm{m} \%\end{array}$ & $\begin{array}{c}\text { Hydrogen / } \\
\mathrm{m} / \mathrm{m} \%\end{array}$ & $\begin{array}{c}\text { Nitrogen / } \\
\mathrm{m} / \mathrm{m} \%\end{array}$ & $\begin{array}{c}\text { Oxygen / } \\
\mathrm{m} / \mathrm{m} \%\end{array}$ \\
\hline Nitrated & a & 21 & 22 & 1 & 3 \\
cardanol & b & 22 & 34 & 0.5 & 1.7 \\
\hline Nitrated & a & 21 & 22 & 1 & 3 \\
polycardanol & b & 20 & 27 & 0.125 & 1.2 \\
\hline Nitrated & a & 15 & 23 & 1 & 3 \\
nonylphenol & b & 16 & 22 & 0.5 & 2 \\
\hline
\end{tabular}

${ }^{\mathrm{a}}$ Average theoretical composition considering $100 \%$ nitration reaction conversion; baverage calculated composition.

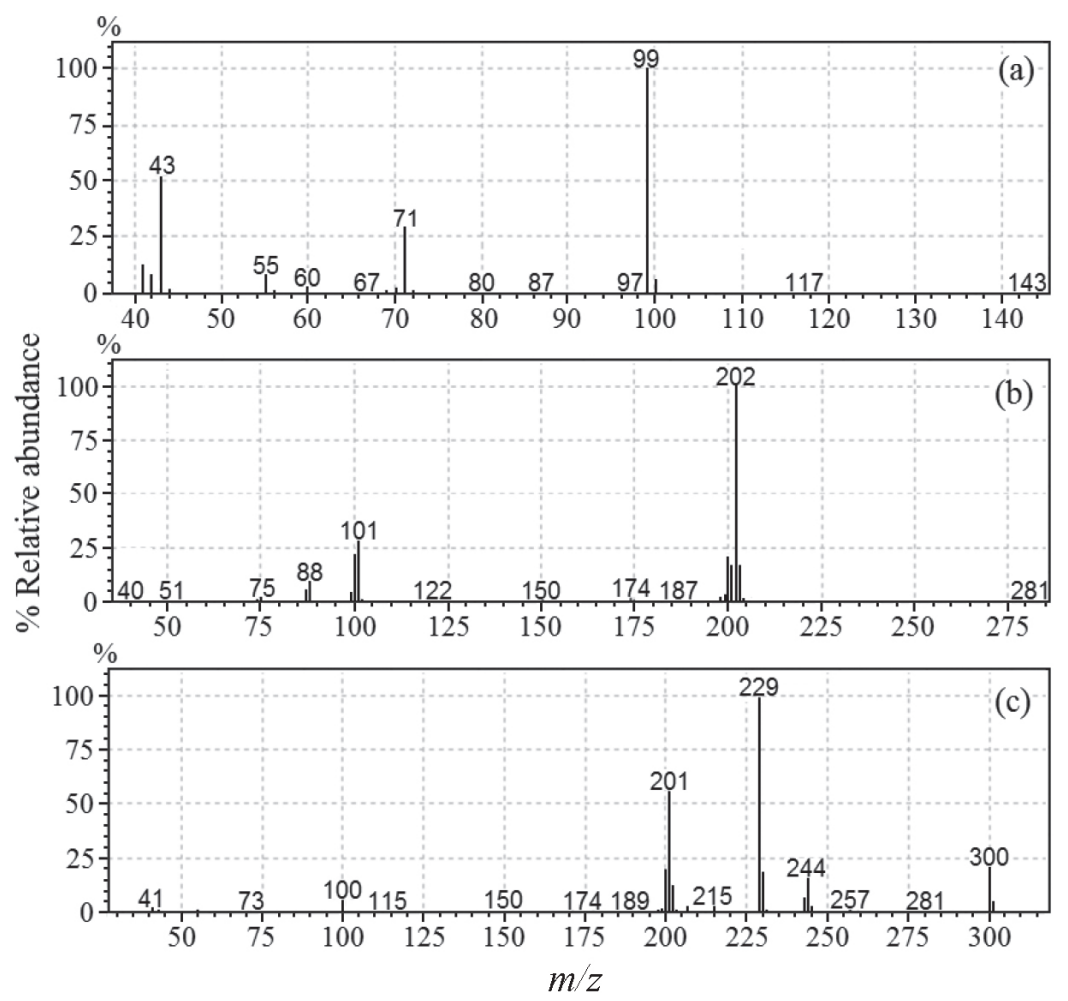

Figure 4. Gas chromatographic spectra coupled to the mass spectrometer (GC-MS): (a) hexanoyl chloride; (b) pyrene and (c) acylated pyrene. 
Evaluation of asphaltenes precipitation onset by nearinfrared spectroscopy (NIR)

As discussed in a previous work, ${ }^{30}$ the addition of enough amount of sample, that exhibit a well-defined curve, will induce a well-defined curve of the sample that present small amount of asphaltenes molecules, as a result of the molecules interactions. Nevertheless, it is important to highlight that such procedure does not lead to the exact value of asphaltenes precipitation onset of the sample. Specifically, it was verified that the addition of oil APS facilitates the identification of the asphaltene precipitation onset of crude oil samples whose curves of absorption intensity versus volume of $n$-heptane titrated are not well defined. Besides this, it was demonstrated that the C3I asphaltene fraction of oil APS, dissolved in toluene at $30 \mathrm{wt}$ \% (similar concentration to this asphaltene fraction in APS), reproduced the behavior of the APS sample, as shown in Table 4.

The model molecules synthesized in this study were dissolved in toluene at varied concentrations and then added to the oil samples in a mass proportion of 80:20 (oil:model solution). By keeping the same proportion used with APS, our objectives here were to obtain: (i) asphaltenes precipitation onset values near those obtained with addition of APS; and (ii) well-defined curves of absorption intensity versus volume of titrated $n$-heptane. We ranked the curves as excellent, fair and poor, as shown in Figures 5a, 5b and 5c. The aspect of the curve of pure APB, rated as fair (Figure 5b), could be modified to excellent or poor in function of the mixture. An excellent curve (Figure 5a) was obtained with addition of $20 \mathrm{wt} . \%$ of APS, while a poor curve (Figure $5 \mathrm{c}$ ) was obtained with addition of $20 \mathrm{wt} . \%$ of PCA at $5 \%$ in toluene.

The molecules were first evaluated in APB, since this crude oil presented a curve for determining the asphaltene precipitation onset that was not as well defined (Figure 5b) as that of sample APA. All the results obtained with APB are summarized in Table 5. In some cases, the curve obtained did not allow determining the precipitation onset, as indicated in Table 5. As a reference, Table 5 includes the onset result of oils APB and APS mixed in 80:20 proportion.
Table 4. Precipitation onset values of pure APA and APB oils with addition of APS oil or $30 \mathrm{wt} . \%$ C3I (APS) solution in toluene

\begin{tabular}{lccc}
\hline $\begin{array}{l}\text { Crude } \\
\text { oil }\end{array}$ & $\begin{array}{c}\text { Oil phase } \\
\text { added to the } \\
\text { crude oil }\end{array}$ & $\begin{array}{c}\text { Proportion } \\
\text { crude:oil phase } / \\
\mathrm{m} / \mathrm{m}\end{array}$ & $\begin{array}{c}\text { Asphaltenes precipitation } \\
\text { onset }( \pm 0.1) / \\
(\mathrm{mL} \text { of } n \text {-heptane } \\
\text { per } \text { g of oil phase) }\end{array}$ \\
\hline APS & - & - & 3.32 \\
\hline APA & - & - & 3.86 \\
\hline & APS & $80: 20$ & 3.30 \\
APB & - & - & 3.35 \\
& APS & $80: 20$ & 1.96 \\
& C3I (30 wt. $\%$ & $80: 20$ & 2.04 \\
\hline
\end{tabular}

Data extracted from reference 30 .

It can be observed that none of the model systems produced a curve as well defined as that of the APB:APS mixture. However, in the great majority of cases, these systems allowed determining the asphaltenes precipitation onset. This was not possible in two different situations: (i) the curve only presented a dilution aspect, i.e., no aggregation was represented. This occurred in the cases of adding acyl pyrene (20\% in toluene), PCC1 (15\% in toluene), PCC2 (15\% in toluene) and PCC3 (15\% in toluene). Figure $6 \mathrm{a}$ shows the curve obtained for APB with addition of PCC3 (at $15 \%$ in toluene) at a proportion of $80: 20 \mathrm{~m} / \mathrm{m}$, illustrating the aspect of the curves obtained in the cases where only dilution was observed. From these results, it can be inferred that the acyl pyrene acted as a stabilizer of the asphaltenes of APB, as did each sample of condensation polycardanol (PCC1, PCC2 and PCC3) at the concentration of $15 \%$ in toluene. In fact, the PCC samples, even at low concentrations $(1.0$ and $5.0 \%$ in toluene), acted to stabilize the asphaltenes, shifting the precipitation onset value of APB to higher values. When the concentration was increased to $15 \%$ in toluene, the onset could no longer be detected, with only the sample dilution curve being observed. (ii) The curve presented an immediate and sharp increase in absorption intensity, i.e., aggregation appeared to be immediately induced. This
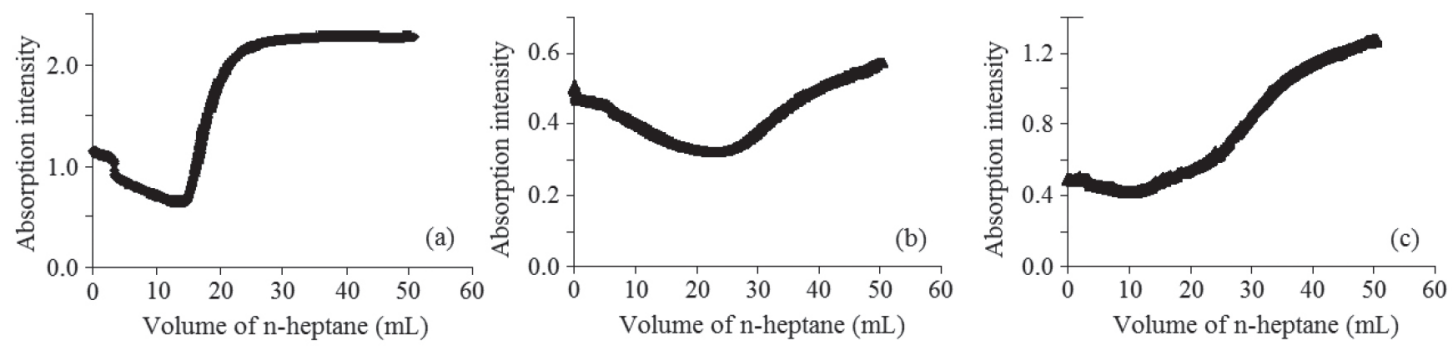

Figure 5. Aspect of the curves of absorption intensity (at $1600 \mathrm{~nm}$ ) versus volume of $n$-heptane: (a) excellent-APB:APS (80:20 m/m); (b) fair-APB; (c) poor-APB:PCA $5 \%$ in toluene $(80: 20 \mathrm{~m} / \mathrm{m})$. 
Table 5. Asphaltenes precipitation onset of crude oil APB with the addition of model molecule dissolved in toluene at various concentrations. Proportion of crude oil:model solution was $80: 20 \mathrm{~m} / \mathrm{m}$

\begin{tabular}{|c|c|c|c|c|}
\hline $\begin{array}{l}\text { Model } \\
\text { molecule }\end{array}$ & $\begin{array}{c}\text { Concentration } \\
\text { of model } \\
\text { molecule } \\
\text { in toluene / } \\
\mathrm{m} / \mathrm{m} \%\end{array}$ & $\begin{array}{l}\text { Proportion } \\
\text { APB:oil } \\
\text { phase / m/m }\end{array}$ & $\begin{array}{c}\text { Onset }( \pm 0.1) / \\
\left(\mathrm{mL} \mathrm{g}^{-1}\right)\end{array}$ & $\begin{array}{l}\text { Curve } \\
\text { aspect }\end{array}$ \\
\hline APB pure & ND & ND & $3.35^{30}$ & fair \\
\hline APS & $\mathrm{ND}^{\mathrm{a}}$ & 80:20 & $1.96^{30}$ & excellent \\
\hline \multirow{3}{*}{ Quinoline } & 5.0 & & 2.97 & fair \\
\hline & 15.0 & & 2.61 & fair \\
\hline & 30.0 & & 2.51 & fair \\
\hline $\begin{array}{l}\text { Acylated } \\
\text { pyrene }\end{array}$ & 20.0 & & ND & $\mathrm{ND}^{\mathrm{b}}$ \\
\hline \multirow{2}{*}{ Cardanol } & 1.0 & & 4.86 & fair \\
\hline & 5.0 & & 4.28 & fair \\
\hline \multirow{5}{*}{$\begin{array}{l}\text { Epoxylated } \\
\text { cardanol }\end{array}$} & 0.5 & & 3.88 & fair \\
\hline & 1.0 & & 3.56 & fair \\
\hline & 5.0 & & 3.79 & fair \\
\hline & 10.0 & & 3.80 & fair \\
\hline & 20.0 & & ND & $\mathrm{ND}^{\mathrm{c}}$ \\
\hline \multirow{6}{*}{$\begin{array}{l}\text { Nitrated } \\
\text { cardanol }\end{array}$} & 0.5 & & 3.01 & fair \\
\hline & 1.0 & & 2.77 & fair \\
\hline & $10.0^{\mathrm{a}}$ & & 2.21 & fair \\
\hline & $15.0^{\mathrm{a}}$ & & 2.24 & fair \\
\hline & 16.0 & & ND & $\mathrm{ND}^{\mathrm{c}}$ \\
\hline & 20.0 & & ND & $\mathrm{ND}^{\mathrm{c}}$ \\
\hline $\mathrm{PCC} 0$ & 1.0 & & 4.54 & fair \\
\hline \multirow{2}{*}{ PCC1 } & 5.0 & & 5.30 & poor \\
\hline & 15.0 & & ND & $\mathrm{ND}^{\mathrm{b}}$ \\
\hline $\mathrm{PCC} 2$ & 15.0 & & ND & $\mathrm{ND}^{\mathrm{b}}$ \\
\hline PCC3 & 15.0 & & ND & $\mathrm{ND}^{\mathrm{b}}$ \\
\hline \multirow{5}{*}{ PCA } & $1.0^{\mathrm{a}}$ & & 1.96 & fair \\
\hline & $2.0^{\mathrm{a}}$ & & 1.99 & fair \\
\hline & 5.0 & & 1.45 & poor \\
\hline & 10.0 & & 1.28 & poor \\
\hline & 15.0 & & ND & $\mathrm{ND}^{\mathrm{c}}$ \\
\hline \multirow{5}{*}{$\begin{array}{l}\text { Nitrated } \\
\text { polycardanol }\end{array}$} & $0.5^{\mathrm{a}}$ & & 2.00 & poor \\
\hline & 1.0 & & 1.27 & poor \\
\hline & 3.0 & & ND & $\mathrm{ND}^{\mathrm{c}}$ \\
\hline & 5.0 & & ND & $\mathrm{ND}^{\mathrm{c}}$ \\
\hline & 15.0 & & ND & $\mathrm{ND}^{\mathrm{c}}$ \\
\hline \multirow{4}{*}{$\begin{array}{l}\text { Nitrated } \\
\text { nonylphenol }\end{array}$} & 0.5 & & 3.02 & fair \\
\hline & 1.0 & & 3.12 & fair \\
\hline & 5.0 & & 3.61 & fair \\
\hline & 15.0 & & 4.53 & poor \\
\hline
\end{tabular}

${ }^{\mathrm{a}}$ Standard crude oil and model molecules presenting the closest results to that of the crude oil; bonly dilution; cimmediate aggregation. Onset: asphaltenes precipitation onset ( $\mathrm{mL}$ of $n$-heptane per $\mathrm{g}$ of oil phase); ND: not detected; PCC: polycardanol obtained by polycondensation; PCA: polycardanol obtained by polyaddition. behavior was observed when adding epoxylated cardanol (20\% in toluene), nitrated cardanol (16 and $20 \%$ in toluene), PCA (15\% in toluene) and nitrated PCA (3, 5 and $15 \%$ in toluene). Figure $6 \mathrm{~d}$ shows the curve obtained for APB with addition of nitrated PCA (at $15 \%$ in toluene) in proportion of $80: 20 \mathrm{~m} / \mathrm{m}$, to illustrate the profile of the curves obtained in these cases. The curves obtained with addition of nitrated polycardanol (PCAN), in the concentration range analyzed (from 0.5 to $15 \%$ in toluene), clearly show that increasing the concentration enhanced the flocculation action, as can be observed from the reduction of the precipitation onset when the polymer concentration was increased from 0.5 to $1.0 \%$ in toluene and by the aspect of the curves in which the precipitation onset cannot be detected (Figures $6 \mathrm{c}$ and $6 \mathrm{~d}$ ).

Still discussing about oil APB, in terms of the asphaltenes precipitation onset value, it was observed that the addition of nitrated cardanol at 10 and $15 \% \mathrm{~m} / \mathrm{m}$ in toluene, PCA at 1 and $2 \% \mathrm{~m} / \mathrm{m}$ in toluene, and nitrated PCA at $0.5 \% \mathrm{~m} / \mathrm{m}$ in toluene caused very similar behavior to that observed with addition of oil APS in this same petroleum. Of note is the advantage of PCA in relation to nitrated cardanol because similar results were obtained with a lower concentration of the former.

It is curious to note that equal onset values were obtained for a single system at varied concentrations in toluene. This same behavior was observed in a previous study, regarding the addition to oil APB of asphaltene fractions C3I or C5I (from oil APS) when the concentration in toluene varied from 15 to $30 \% .{ }^{30}$ This same behavior was also observed for addition to APB of quinoline at 15 and $30 \%$ in toluene (Table 5), which led to onset values of 2.61 and $2.51 \mathrm{~mL}$ of $n$-heptane per g of oil, respectively, i.e., virtually equal values for different concentrations, considering analytical error of $\pm 0.1 \mathrm{~mL} \mathrm{~g}^{-1}$.

Some of the molecules were also tested in APA oil to check whether the behavior observed in APB would be repeated in another crude oil. All these results are summarized in Table 6. The systems that when added to APA led to onset values almost equal to that of the APA:APS $(80: 20 \mathrm{~m} / \mathrm{m})$ mixture were quinoline at $30 \%$ in toluene, nitrated cardanol at $20 \%$ in toluene and PCA (addition polycardanol) at $1 \%$ in toluene. The nitrated cardanol at $15 \%$ in toluene and nitrated PCA at $0.5 \%$ in toluene led to onset values very close to those obtained for the APA:APS mixture. As observed in Table 5, polycardanol stood out in relation to nitrated cardanol because of the lower concentration needed to attain similar results.

Comparison of the results of Tables 5 and 6 shows that the same molecule at the same concentration in toluene can lead to different behaviors in the two crude oils (APA and APB), with exception of PCA (at $1 \%$ in toluene) and 

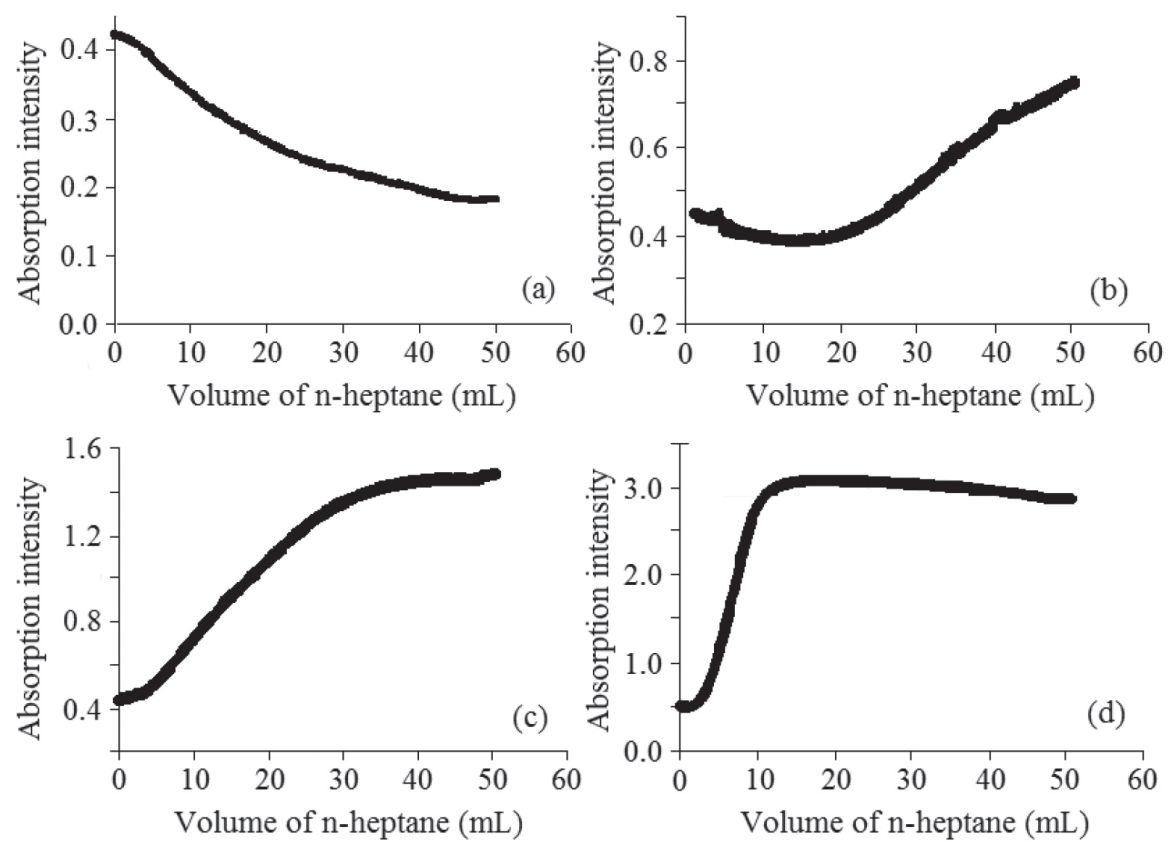

Figure 6. Absorption intensity (at $1600 \mathrm{~nm}$ ) versus volume of $n$-heptane for crude oil APB:model systems (80:20 m/m), using the following model systems: (a) PCC 3 at $15 \%$ in toluene; (b) PCAN at $0.5 \%$ in toluene; (c) PCAN at $3 \%$ in toluene and (d) PCAN at $15 \%$ in toluene.

Table 6. Asphaltenes precipitation onset of crude oil APA with the addition of model molecule dissolved in toluene at various concentrations. Proportion of crude oil:model solution was $80: 20 \mathrm{~m} / \mathrm{m}$

\begin{tabular}{lcccc}
\hline $\begin{array}{l}\text { Model } \\
\text { molecule }\end{array}$ & $\begin{array}{c}\text { Concentration } \\
\text { of model } \\
\text { molecule } \\
\text { in toluene } / \\
\mathrm{m} / \mathrm{m} \%\end{array}$ & $\begin{array}{c}\text { Proportion } \\
\text { APB:oil } \\
\text { phase / } / \mathrm{m} / \mathrm{m}\end{array}$ & $\begin{array}{c}\text { Onset }( \pm 0.1) / \\
\left(\mathrm{mL} \mathrm{g}^{-1}\right)\end{array}$ & $\begin{array}{c}\text { Curve } \\
\text { aspect }\end{array}$ \\
\hline APA pure & $\mathrm{ND}$ & $\mathrm{ND}$ & 3.86 & excellent \\
\hline APS & $\mathrm{ND}^{\mathrm{a}}$ & $80: 20$ & 3.30 & excellent \\
\hline Quinoline & $30.0^{\mathrm{a}}$ & & 3.23 & excellent \\
\hline Nitrated & 15.0 & & 3.49 & excellent \\
cardanol & $20.0^{\mathrm{a}}$ & & 3.29 & excellent \\
\hline & $1.0^{\mathrm{a}}$ & & 3.25 & excellent \\
PCA & 5.0 & & 2.40 & excellent \\
& 10.0 & & 1.92 & fair \\
& 15.0 & & 1.76 & fair \\
\hline & $0.5^{\mathrm{a}}$ & & 3.56 & excellent \\
Nitrated & 1.0 & 3.11 & excellent \\
polycardanol & 5.0 & 1.72 & excellent \\
& 10.0 & 1.08 & excellent \\
\hline
\end{tabular}

$\overline{\text { a Standard crude oil and model molecules presenting the closest results }}$ to that of the crude oil. Onset: asphaltenes precipitation onset $(\mathrm{mL}$ of $n$-heptane per g of oil phase); PCA: polycardanol obtained by polyaddition.

nitrated PCA (at $0.5 \%$ in toluene), which led to desired onset values in both oils.

Two molecules (nitrated cardanol and PCA) were used to assess the determination of the asphaltenes precipitation onset of a crude oil (APX) whose absorption intensity versus $n$-heptane volume curve was not well defined, thus preventing determining the onset. For comparison, the test was also performed with addition of APS in proportion of $80: 20 \mathrm{~m} / \mathrm{m}$ of APX:APS. The onset result was $1.83 \mathrm{~mL}$ of $n$-heptane per $\mathrm{g}$ of oil (Table 7). The addition of nitrated cardanol at $20 \%$ in toluene to oil APX in the same proportion $(80: 20 \mathrm{~m} / \mathrm{m})$ allowed determining a precipitation onset of $1.72 \mathrm{~mL}$ of $n$-heptane per $\mathrm{g}$ of oil, a result similar to that of the mixture with APS, considering the analytic error. The PCA at $1 \% \mathrm{~m} / \mathrm{m}$ in toluene was added to APX in $80: 20 \mathrm{~m} / \mathrm{m}$ proportion and only a dilution curve was obtained.

Table 7. Asphaltenes precipitation onset of crude oil APX with the addition of model molecule dissolved in toluene. Proportion of crude oil:model solution was $80: 20 \mathrm{~m} / \mathrm{m}$

\begin{tabular}{lcccc}
\hline $\begin{array}{l}\text { Model } \\
\text { molecule }\end{array}$ & $\begin{array}{c}\text { Concentration } \\
\text { of model } \\
\text { molecule } \\
\text { in toluene / } \\
\mathrm{m} / \mathrm{m} \%\end{array}$ & $\begin{array}{c}\text { Proportion } \\
\text { APB:oil } \\
\text { phase / } / \mathrm{m}\end{array}$ & $\begin{array}{c}\text { Onset }( \pm 0.1) / \\
\left(\mathrm{mL} \mathrm{g}^{-1}\right)\end{array}$ & $\begin{array}{c}\text { Curve } \\
\text { aspect }\end{array}$ \\
\hline $\begin{array}{l}\text { APX pure } \\
\text { APS }^{\mathrm{a}}\end{array}$ & $\mathrm{ND}$ & $\mathrm{ND}$ & $\mathrm{ND}$ & $\mathrm{ND}$ \\
$\begin{array}{l}\text { Nitrated } \\
\text { cardanol }\end{array}$ & $\mathrm{ND}$ & & $1.83^{30}$ & fair \\
& 20.0 & & 1.72 & fair \\
PCA & 0.1 & $80: 20$ & $\mathrm{ND}^{\mathrm{b}}$ & $\mathrm{ND}^{\mathrm{b}}$ \\
& 1.0 & & $\mathrm{ND}$ & $\mathrm{ND}^{\mathrm{b}}$ \\
& 20.0 & & $\mathrm{ND}$ & $\mathrm{ND}^{\mathrm{b}}$ \\
\hline
\end{tabular}

${ }^{\text {aStandard crude; }}$ bonly dilution. Onset: asphaltenes precipitation onset (mL of $n$-heptane per g of oil phase); ND: not detected; PCA: polycardanol obtained by polyaddition. 
The molecules that when added to the oil samples presented precipitation onset results nearest to those of the target oil + APS mixture were investigated regarding their solubility parameter ranges. The molecules of nitrated cardanol, polycardanol (PCA) and nitrated polycardanol (PCAN) were dissolved at $30 \%$ in toluene (concentration similar to the C3I fraction in APS) and titrated separately with $n$-heptane and with ethanol. These results are presented in Table 8, together with those obtained previously ${ }^{30}$ for the C3I (from oil APS) in toluene for comparison. It can be seen that these samples presented the same or very close solubility behavior to that of fraction C3I from oil APS.

Table 8. Solubility parameter ranges for samples C3I, nitrated cardanol, PCA and nitrated polycardanol

\begin{tabular}{lll}
\hline Molecule & $\delta_{\text {lower }}$ & $\delta_{\text {upper }}$ \\
\hline C3I APS $^{30}$ & 15.9 & 19.6 \\
Nitrated cardanol & 15.8 & 20.0 \\
PCA & 16.0 & 20.5 \\
Nitrated polycardanol & 17.8 & ND \\
\hline
\end{tabular}

$\delta_{\text {lower }}$ : obtained from the titration of the model solution (at $30 \%$ in toluene) with $n$-heptane; $\delta_{\text {upper }}$ : obtained from the titration of the model solution (to $30 \%$ in toluene) with ethanol; PCA: polycardanol obtained by polyaddition; ND: the test was not done.

\section{Conclusions}

The asphaltenes precipitation onset points of crude oil samples that do not have well-defined curves of absorption intensity in function of volume of titrated $n$-heptane can be ascertained by adding a solution of toluene containing an additive whose molecules have similar groups to those found in asphaltenes: aromatic ring, aliphatic chain and heteroatom. Nitrated cardanol, polycardanol (by polyaddition) and nitrated polycardanol presented this behavior when dissolved in toluene. The quantity of the model system added does not need to exceed the proportion of $80: 20 \mathrm{~m} / \mathrm{m}$ (oil:model system). However, the concentration of the additive in toluene should be adjusted in function of the characteristics of the crude oil, and for the same oil, the greater the solubility parameter range is of the model molecule, the lower the concentration necessary to identify the precipitation onset of the petroleum will be. Molecules that at a determined concentration have a strong stabilizing or flocculant effect are not suitable for this type of test because they only generate dilution curves or show immediate aggregation, respectively.

\section{Acknowledgments}

We thank CNPq (307193/2016-0), CAPES,
FAPERJ (E-26/201.233/2014), ANP and Petrobras (0050.0086965.13.9) for financial support.

\section{References}

1. Holmes, J. W.; Bullin, J. A.; Hydrocarbon Process. 1983, 101.

2. Schermer, W. E. M.; Melein, P. M. J.; van den Berg, F. G. A.; Pet. Sci. Technol. 2004, 22, 1045.

3. Moura, L. G. M.; Santos, M. F. P.; Zilio, E. L.; Rolemberg, M. P.; Ramos, A. C. S.; J. Pet. Sci. Eng. 2010, 74, 77.

4. Moura, L. G. M.; Rolemberg, M. P.; Ramos, A. C. S.; Santos, M. F. P.; Zilio, E. L.; Quim. Nova 2001, 34, 226.

5. Wiehe, I. A.; Energy Fuels 2012, 26, 4004.

6. Ramos, A. C. S.; Rolemberg, M. P.; Moura, L. G. M.; Zilio, E. L.; Santos, M. F. P.; González, G.; J. Pet. Sci. Eng. 2013, 102, 36.

7. Santos, D. C.; Filipakis, S. D.; Rolemberg, M. P.; Lima, E. R. A.; Paredes, M. L. L.; Fuel 2017, 199, 606.

8. Marques, L. C. C.; Pereira, J. O.; Bueno, A. D.; Marques, V. S.; Lucas, E. F.; Mansur, C. R. E.; Machado, A. L. C.; González, G.; J. Braz. Chem. Soc. 2012, 23, 1880.

9. Honse, S. O.; Mansur, C. R. E.; Lucas, E. F.; J. Braz. Chem. Soc. 2012, 23, 2204.

10. Mansur, C. R. E.; Melo, A. R.; Lucas, E. F.; Energy Fuels 2012, 26, 4988.

11. Aguiar, J. I. S.; Mansur, C. R. E.; Fuel 2015, 140, 462.

12. Hartmann, D.; Lopes, H. E.; Teixeira, C. L. S.; Oliveira M. C. K.; Gonzalez, G.; Lucas, E. F.; Spinelli, L. S.; Energy Fuels 2016, 30, 3693.

13. Mansoori, G. A.; Jiang, T. S.; Kawanaka, S.; Arabian J. Sci. Eng. 1988, 13, 7.

14. Gray, M. R.; Upgrading Petroleum Residues and Heavy Oils; Marcel Dekker: New York, 1994.

15. Sousa, M. A.; Oliveira, G. E.; Lucas, E. F.; González, G.; Prog. Colloid Polym. Sci. 2004, 128, 283.

16. Mullins, O. C.; Sheu, E. Y.; Hammami, A.; Marshal, A. G.; Asphaltenes, Heavy Oils, and Petroleomics; Springer: New York, 2007.

17. Wiehe, I. A.; Kennedy, R. J.; Energy Fuels 2000, 14, 56.

18. Wiehe, I. A.; Kennedy, R. J.; Energy Fuels 2000, 14, 60.

19. Redelius, P.; Energy Fuels 2004, 18, 1087.

20. Mohammadi, A. H.; Richon, D.; AIChE J. 2007, 53, 2940.

21. Hansen, C. M.; Hansen Solubility Parameters: A User's Handbook, $2^{\text {nd }}$ ed.; CRC Press: New York, 2007.

22. Garreto, M. S. E.; Gonzalez, G.; Ramos, A. C.; Lucas, E. F.; Chem. Chem. Technol. 2010, 4, 317.

23. Ferreira, S. R.; Barreira, F. R.; Spinelli, L. S.; Seidl, P.; Leal, K. Z.; Lucas, E. F.; Quim. Nova 2016, 39, 26.

24. Lucas, E. F.; Mansur, C. R. E.; Spinelli, L. S.; Queirós, Y. G. C.; Pure Appl. Chem. 2009, 81, 476.

25. Garreto, M. S. E.; Mansur, C. R. E.; Lucas, E. F.; Fuel 2013, 113,318 . 
26. Palermo, L. C. M.; Souza Jr., N. F.; Louzada, H. F.; Bezerra, M. C. M.; Spinelli, L. S.; Lucas, E. F.; Braz. J. Pet. Gas 2014, 7,181 .

27. Ferreira, S. R.; Louzada, H. F.; Dip, R. M. M.; Gonzalez, G.; Lucas, E. F.; Energy Fuels 2015, 29, 7213.

28. Lucas, E. F.; Ferreira, L. S.; Khalil, C. N.; Encyclopedia of Polymer Science and Technology; Mark, H. F., ed.; John Wiley \& Sons, Inc.: New York, 2015, p. 12344.

29. Palermo, L. C. M.; Lucas, E. F.; Energy Fuels 2016, 30, 3941.

30. Barreira, F. R.; Reis, L. G.; Nunes, R. P.; Filipakis, S. D.; Lucas, E. F.; Energy Fuels 2018, 32, 10391.

31. Wiehe, I. A.; Rahimi, P.; Oh, Y. D.; McNamara, R.; Alem, T.; Energy Fuels 2008, 22, 753.

32. Freund, H.; Walters, C. C.; Kelemen, S. R.; Siskin, M.; Gorbaty, M. L.; Curry, D. J.; Bence, A. E.; Org. Geochem. 2007, 38, 288.

33. Kuznicki, T.; Masliyah, J. H.; Bhattacharjee, S.; Energy Fuels 2008, 22, 2379.

34. Kelland, M. A.; Production Chemicals for the Oil and Gas Industry; CRC Press: Boca Raton, 2009.

35. Kuznicki, T.; Masliyah, J. H.; Bhattacharjee, S.; Energy Fuels 2009, 23, 5027.

36. Ramírez, F. A.; Moralez, Y. R.; Energy Fuels 2013, 27, 1791.

37. Jian, C.; Tang, T.; Bhattacharjee, S.; Energy Fuels 2013, 27, 2057.

38. Sjoblom, J.; Simon, S.; Xu, Z.; Adv. Colloid Interface Sci. 2015, $128,1$.

39. Siskin, M.; Kelemen, S. R.; Eppig, C. P.; Brown, L. D.; Afeworki, M.; Energy Fuels 2006, 20, 1227.

40. Horton, S. R.; Hou, Z.; Moreno, B. M.; Bennett, C. A.; Klein, M. T.; Sci. China: Chem. 2013, 56, 840.

41. Groenzin, H.; Mullins, O. C.; Energy Fuels 2000, 14, 677.

42. Boek, E. S.; Yakovlev, D. S.; Headen, T. F.; Energy Fuels 2009, 23, 1209.

43. Devard, A.; Pujro, R.; Puente, G.; Sedran, U.; Energy Fuels 2012, 26, 5015.
44. Cardozo, S. D.; Schulze, M.; Tykwinski, R. R.; Gray, M. R.; Energy Fuels 2015, 29, 1494.

45. Schulze, M.; Lechner, M. P.; Stryker, J. M.; Tykwinski, R. R.; Org. Biomol. Chem. 2015, 13, 6984.

46. Rakotondradany, F.; Fenniri, H.; Rahimi, P.; Gawrys, K. L.; Kilpatrick, P. K.; Gray, M. R.; Energy Fuels 2006, 20, 2439.

47. Tan, X.; Fenniri, H.; Gray, M. R.; Energy Fuels 2007, 22, 715.

48. Nordgard, E. L.; Sorland, G.; Sjoblom, J.; Lagmuir 2009, 26, 2352.

49. Alshareef, A. H.; Scherer, A.; Stryker, J. M.; Tykwinsky, R.; Gray, M. R.; Energy Fuels 2012, 26, 3592.

50. Teklebrhan, R. B.; Ge, L.; Bhattacharjee, S.; Xu, Z.; Sjoblom, J.; J. Phys. Chem. B 2012, 116, 5907.

51. Zhang, L.; Greenfield, M. L.; Energy Fuels 2008, 22, 3363.

52. Gray, M. R.; Upgrading Oilsands Bitumen and Heavy Oil; The University of Alberta Press: Alberta, 2015.

53. Bloise, E.; Carbone, L.; Colafemmina, G.; Accolti, L. D'.; Mazzetto, S. E.; Vasapollo, G.; Mele, G.; Molecules 2012, 17, 12252.

54. Altoé, R.; Oliveira, M. C. K.; Lopes, H. E.; Teixeira, C.; Cirilo, L. C. M.; Lucas, E. F.; Gonzalez, G.; Colloids Surf., A 2014, $445,59$.

55. Aguiar, J. I. S.; Garreto, M. S. E.; González, G.; Lucas, E. F.; Mansur, C. R. E.; Energy Fuels 2014, 28, 409.

56. Loureiro, T.; Dip, R. M. M.; Lucas, E.; Spinelli, L.; J. Polym. Environ. 2018, 26, 555.

57. Silverstein, R. M.; Webster, F. X.; Kiemle, D. J.; Identificação Espectrométrica de Compostos Orgânicos; John Wiley \& Sons, Inc.: New York, 2013, p. 70.

Submitted: October 29, 2018 Published online: February 5, 2019 